1. MBBS

Post Graduate Surgery King Edward Medical University Mayo Hospital Lahore.

2. MBBS, FCPS

Senior Registrar Surgery

King Edward Medical University Lahore.

3. MBBS, FCPS, MRCS, MS

Professor of Surgery

King Edward Medical University Lahore.

4. MBBS

Post Graduate Resident General Surgery

King Edward Medical University Lahore.

5. MBBS

Post Graduate Resident General Surgery

King Edward Medical University Lahore.

6. MBBS

Post Graduate Resident General Surgery

DHQ Hospital Faisalabad.

Correspondence Address:

Dr. Mohammad Sohail Asghar

Department of Surgery

King Edward Medical University Mayo

Hospital Lahore.

Kdark7582@gmail.com

Article received on:

11/01/2020

Accepted for publication:

03/04/2020

\section{OUTCOME OF ONE YEAR'S EXPERIENCE OF THYROID SURGERY IN A HIGH VOLUME CENTER.}

\begin{abstract}
Mohammad Sohail Asghar ${ }^{1}$, Ahmad Kaleem², Ameer Afzal ${ }^{3}$, Usama Shabbir ${ }^{4}$, Jamal Anwar ${ }^{5}$, Mohammad Sohaib Asghar ${ }^{6}$

ABSTRACT... Objectives: This study was performed to take an overview of the modes of presentation of these disorders, demographic factors of presenting patients, procedures to deal with these disorders and complications associated with them in our surgical ward. Study Design: Cross Sectional Study. Setting: Department of North Surgery, Mayo Hospital Lahore Pakistan. Period: September 2018 to September 2019. Material \& Methods: All adult patients of either gender who presented with benign or malignant thyroid disorders and were managed surgically during the study period were included. The data was recorded on a pre-designed proforma maintained at the department. Results: Out of 156 patients, there were 146(93.6\%) females and 10(6.4\%) males. The most commonly performed procedure was total thyroidectomy i.e 102 (65.3\%) while hemi thyroidectomies being 41 (26.1\%). We performed 4 neck dissections in this time period for malignancies. The mean hospital stay ranged from 1-12 days with a mean of $2.88 \pm 1.99$ days. There was no in-hospital mortality. Temporary hypocalcemia was the most common early complication found in 32(20.5\%) patients. Conclusion: Thyroid surgery is a safe procedure to be performed for teaching purposes in a high volume unit like ours with complication rates reaching near zero.
\end{abstract}

Key words: $\quad$ Hight Volume, Hypocalcemia, RLN Injury, Thyroid.

Article Citation: Asghar MS, Kaleem A, Afzal A, Shabbir U, Anwar J, Asghar S. Outcome of one year's experience of thyroid surgery in a high volume center. Professional Med J 2020; 27(10):2081-2087. DOI: 10.29309/TPMJ/2020.27.10.4479

\section{INTRODUCTION}

Thyroidectomy is a commonly performed surgical procedure in which a whole or some part of the thyroid is removed to treat various disorders. Thyroidectomy is a common operation performed for both benign and malignant conditions of thyroid with an extremely low mortality. ${ }^{1}$ It is associated with specific morbidities which are related to the experience of the surgeon, however. Very low surgical morbidity rates are reported in specialized centers. ${ }^{2}$

The main complications present day associated with thyroidectomy are hypoparathyroidism and recurrent laryngeal nerve after we have overcome the complications of bleeding, sepsis, and hypothyroidism after a long journey from the start of this operation.

The presence of the thyroid nodules when checked by clinical examination is $4-8 \%$ and when detected sonographically is $13-67 \%$. Different studies have shown that thyroid nodules were present in $50 \%$ of the general population on autopsy. ${ }^{3}$ The development of thyroid nodules is more among females, endemic areas. 5\% of thyroid nodules harbor malignancy. The occurrence of malignancy is more in solitary thyroid nodules (STN) compared to multinodular goiter. ${ }^{4}$ Fine needle aspiration biopsy is the best technique to diagnose thyroid nodules with a diagnostic accuracy of $98 \%$ and $<2 \%$ false positive and false negative result. ${ }^{5}$

Our country is surrounded by Himalayas and Karakoram ranges which are known to be iodinedeficient and that why we encounter almost every type of thyroid disorder in our hospitals. ${ }^{6}$ This study was performed to take an overview of the modes of presentation of these disorders, demographic factors of presenting patients, procedures to deal with these disorders and complications 
associated with them in our surgical ward.

\section{MATERIAL \& METHODS}

This audit was done at the North Surgery Department, Mayo Hospital Lahore Pakistan, from September 2018 to September 2019. All the patients of either gender having any benign or malignant thyroid condition and had thyroid surgery of any kind during this duration were included. The data collected and recorded with the help of pre-designed proforma and were analyzed on SPSS 20. The variables like demographics, presenting complaints like dyspnea, dysphagia, hoarseness of voice, duration of the disease, family history, function of thyroid gland on labs, type of surgery were seen. The outcomes like complications, hospital stay, and in-hospital mortality were assessed. Diagnosis was made on the basis of history, examination and ancillary investigations (Thyroid function tests [TFTs] and pre-operative indirect laryngoscopy [IDL] in all patients, and other tests in selected cases such as $99 \mathrm{~m}$ Technetium thyroid scan for toxic goiters, fine needle aspiration cytology [FNAC] for solitary, dominant and cold nodules, X-ray thoracic inlet for retrosternal extension in huge goiters, serum thyroglobulin and anti-thyroid antibodies, etc where indicated). All patients with disturbed functioning were rendered euthyroid before subjecting them to surgery. All patients were hospitalized for surgery. The operative procedures undertaken were tailored according to the type of thyroid disorders and included lobectomy with isthmusectomy (for clinically solitary nodules in the ipsilateral lobe with benign FNAC), subtotal thyroidectomy/ total thyroidectomy (for bilateral nodularity, diffuse goiters, Hashimoto's thyroiditis, and Graves' disease), and near-total thyroidectomy (for solitary nodules in the ipsilateral lobe with inconclusive FNAC or cold nodules on thyroid scan). Post-operatively the patients had clinical and biochemical evaluation for hypocalcemia. The status of the recurrent laryngeal nerve (RLN) was assessed from the voice of the patient and IDL. The target follow-up period was one year, with scheduled visits at 3-month intervals. If hypocalcemia persisted beyond 6 months, it was regarded as permanent. Similarly, if RLN palsy persisted for over six months, it was considered permanent.

\section{RESULTS}

Out of 156 patients, there were 146(93.6\%) females and $10(6.4 \%)$ males.

Overall mean age was $36.44 \pm 9.86$ years (range: 16-65 years). The majority $(n=148)$ belonged to Lahore, Sheikhupura, Gujranwala and other districts in the immediate periphery of Lahore, and adjoining districts of Punjab.

Family history of thyroid disorders was positive in none of these patients.

Among the presenting features, 98(62\%) patients had various symptoms due to local pressure effects of the goiter in the form of dyspnea, dysphagia, and hoarseness of voice, 85(55.1\%) had features of toxicity, $27(5.12 \%)$ had anxiety about neck lump, while $58(36.9 \%)$ had cosmetic concerns.

The duration of disease ranged from 2.5-25 years with a mean of $11.85 \pm 3.41$ years.

Among the total patients with multinodular goiters i.e $n=115 \% 73 \%$, hyperthyroid were 80 , hypothyroid were 22 and euthyroid were 13.

Among the 41 patients with solitary nodules, euthyroid were 32, hyperthyroid were 6 and hypothyroid were 3 patients.

\begin{tabular}{|l|c|c|c|c|}
\hline \multicolumn{1}{|c|}{ Nodularity } & Euthyroid & Hyperthyroid & Hypothyroid & Total \\
\hline MNG & 13 & 80 & 22 & 115 \\
\hline STN & 32 & 6 & 3 & 41 \\
\hline Total & & & & 156 \\
\hline
\end{tabular}


The pre-operative IDL was unremarkable in all patients. Overall, FNAC was performed on 49 (31.41\%) patients with solitary nodules, dominant nodules and cold nodules/areas detected on thyroid scan.

Regarding comorbidities, the patients with hypertension were 50 (32.05\%), with diabetes mellitus were $10(6.41 \%)$ and with asthma were $6(3.8 \%)$. More than one of these comorbidities were present in $8(5.1 \%)$ patients.

On the final biopsy of the specimens total benign cases were 151 i.e $96.7 \%$ and malignant cases were 5.

The most commonly performed procedure was total thyroidectomy i.e 102 (65.3\%) while hemi thyroidectomies being 41 (26.1\%). We performed 4 neck dissections in this time period for malignancies. 10 patients had near-total or subtotal thyroidectomies. All these patients were from the old age group i.e. mean $=54.32 \pm 4.5$ years All the cases turned out to be benign ones on the final biopsy of specimen except one patient who had small papillary tumor islands. She did not have any lymph nodes positive during surgery. She was referred to the oncology department.

The mean hospital stay ranged from 1-12 days with a mean of $2.88 \pm 1.99$ days. There was no inhospital mortality. Temporary hypocalcemia was the most common early complication found in $32(20.5 \%)$ patients.

\section{DISCUSSION}

lodine deficiency is undisputedly the most common cause of goiter worldwide as is true for the region we are living in. ${ }^{7}$ Simple diffuse goiter, which is by far the commonest thyroid disorder, is a physiological entity and has a high prevalence among the premenopausal female age group. On the other hand, thyroid nodules are formed as the age increases and are more common among the males. ${ }^{8}$ Thyroid nodules can be benign or malignant.

Currently, total thyroidectomy is considered a safe procedure but it has many potential complications. Some of these, if not treated in time, can prove fatal while some of these like nerve injuries and hypoparathyroidism have significant postoperative morbidity. Surgeon's experience, operating technique, extent of resection are the factors influencing the outcome of the patients undergoing thyroidectomies. It is evident that by keeping in view these factors we can minimize the occurrence of these complications at specialized centers performing high volumes of thyroidectomies. ${ }^{9}$

\begin{tabular}{|c|l|c|c|}
\hline \multicolumn{1}{|c|}{ Procedure } & Frequency & Percentage \\
\hline 1 & Total thyroidectomy & 102 & 65.3 \\
\hline 2 & Lobectomy & 41 & 26.1 \\
\hline 3 & Near-total thyroidectomy & 5 & 3.2 \\
\hline 4 & Subtotal thyroidectomy & 4 & 2.5 \\
\hline 5 & Total Thyroidectomy+Neck Dissection & 4 & 2.5 \\
\hline & Total & 156 & 100 \\
\hline Sr. Complication & & Frequency & Percentage \\
\hline 1 & Transient hypocalcemia & 32 & 20.5 \\
\hline 2 & Hoarseness & 10 & 6.4 \\
\hline 3 & RLN Injury & 1 & 0.6 \\
\hline 4 & Bleeding & 1 & 0.6 \\
\hline 5 & Seroma & 0 & 0 \\
\hline 6 & Infection & 0 & 0 \\
\hline 7 & Scar problem & 0 & 0 \\
\hline
\end{tabular}


In our study, females were most affected by thyroid disorders i.e $n=146(93 \%)$ while there were only 10 cases of male patients operated for thyroid diseases. These findings like our study are also shown by Yan et al. that out of 7385 patients who had thyroidectomy, $71 \%$ of these were female ${ }^{10}$ while Huang et al. showed in their study that among 3428 patients who had thyroidectomy, the ratio being female to male as $5.24: 1$. The mean age of these patients was 40 years and above. ${ }^{11}$ In fact, many other studies also showed a higher incidence of thyroid disorders among females. ${ }^{12}$

Relatively younger age group presented in higher numbers as compared to the older age group. The average age was 36.6 years with a number of patients in their teens. It is comparable to many other studies too. ${ }^{12}$

Multinodular goiter was the most common presentation in our patients which is in accordance with other published studies overall. This is probably related to a large number of iodine-deficient areas as well as delay in seeking surgical care. ${ }^{13,14}$ There was one case of Pendred syndrome where a young female patient had MNG along with bilateral deafness since birth.

Toxic symptoms were present in most of our cases for which they have been on anti-thyroid drugs and they were rendered euthyroid before putting them on the list for surgery. Other studies have shown that hypothyroidism is more common among the patients with goiters.

The overall postoperative complication rate in this study was $28.8 \%$ which included mostly transient complications. Only one patient had right recurrent laryngeal nerve injury and it was identified and repaired by the team of the plastic surgeon. Apart from that none of these patients had any permanent complications which affected them adversely after one week of surgery. Literature reports varying rates of thyroidectomy related complications. Although some authors have reported a lower overall rate of complication than in this study, all have reported permanent complications; there was only one case of permanent complication in this study. On the other hand, we reported a lower rate of complication than many other studies in the literature. ${ }^{15-17}$

The most common postoperative complication of thyroidectomy is hypocalcemia, either symptomatic or asymptomatic. Hypocalcemia is most commonly caused by postoperative parathyroid insufficiency due to incidental removal of one or more glands, stunning and devascularization of the glands. However, transient postoperative hypocalcemia can occur as a result of haemodilution, increased urinary excretion due to surgical stress, calcitonin release and hungry bone syndrome in patients with hyperthyroidism. ${ }^{18,19}$ In this study, the rate of hypocalcemia was $20.5 \%$. None of those hypocalcemic patients required calcium supplements after 1 week. Some authors have reported a lower incidence of postoperative hypocalcemia than we reported in this study (as low as $3.5 \%)^{19,20}$ whereas several other studies have reported a higher incidence of hypocalcemia (as high as 59\%). ${ }^{19}$ Suwannasarn et al. reported immediate hypocalcemia was observed in $38.5 \%$ of patients. ${ }^{21}$ Early postoperative hypocalcemia was $42 \%$ in Seo et al study. ${ }^{22}$ The majority of studies with lower rates have encountered some form of permanent hypoparathyroidism (hypocalcemia), which greatly impairs the patient's quality of life. In comparison, we did not encounter any permanent hypocalcemia. All patients with transient hypocalcemia did not require calcium supplements after 1 week. The overall incidence in this study is on the lower side of the reported data in the literature; more significantly, we have achieved the lowest possible rate of permanent hypocalcemia. ${ }^{23,24}$

Recurrent laryngeal nerve palsy may be the result of a number of iatrogenic injury mechanisms. For instance, it may be caused by direct section, thermal injury by cautery or by suture entrapment of the nerve. It may also be secondary to neuropraxia or the formation of perineural fibrous tissue.

The best way to safeguard the nerve is to either stay away from its course as in subtotal thyroidectomy or to identify it to its fullest extent as 
in total thyroidectomy. In special situations where its dissection appears very difficult, A Section of the isthmus of the thyroid and its release in the mediolateral direction can be helpful.

In our study, one patient had RLN injury which was identified on the table and was repaired by the team of plastic surgeons. The patient did not have any respiratory issues postoperatively and was discharged on $4^{\text {th }}$ postoperative day with normal voice quality. So RLN injury in our study was only $0.6 \%$ which is much lower than the recognized incidence of nerve injuries. ${ }^{25-27}$ Some patients had postoperative hoarseness (7.1\%) which improved before the first follow up visit.

We came across one patient with postoperative bleeding. This was re-explored immediately, a small hematoma was found and a small bleeding vessel was ligated; the patient's condition was not compromised with a smooth post-operative course. Our rate of postoperative bleeding is well within the incidence range reported in the international literature of $0 \%$ to $5 \%{ }^{28}$ a recent American study reported an incidence of $2.3 \% .^{29}$

Average post-op hospital stay in our study was 2.82 days with SD 1.99. Most of the patients who stayed in the ward for more than 2 days were those who underwent total thyroidectomy or more extensive surgery. There has been some work on outpatient thyroid surgery but its safety and costeffectiveness are not yet clearly proved. ${ }^{30,31}$

\section{CONCLUSION}

Thyroid surgery is a safe procedure to be performed for teaching purposes in a high volume unit like ours with complication rates reaching near zero. But this study has the following strengths and limitations.

\section{LIMITATIONS}

- One year's record only.

- No optimal long term follow up taken into account.

Copyright@ 03 Apr, 2020.

\section{REFRENCES}

1. Padur AA, Kumar N, Guru A, Badagabettu SN, Shanthakumar SR, Virupakshamurthy MB, et al. Safety and effectiveness of total thyroidectomy and its comparison with subtotal thyroidectomy and other thyroid surgeries: A Systematic Review. J Thyroid Res. 2016; 2016:7594615-.

2. Makay Ö. Less than total thyroidectomy for goiter: When and how? Gland Surg. 2017; 6(Suppl 1):S49-S58.

3. Tamhane S, Gharib H. Thyroid nodule update on diagnosis and management. Clin Diabetes Endocrinol. 2016; 2:17-.

4. Jena A, Patnayak R, Prakash J, Sachan A, Suresh V, Lakshmi AY. Malignancy in solitary thyroid nodule: A clinicoradiopathological evaluation. Indian journal of endocrinology and metabolism. 2015; 19(4):498-503.

5. Lai SW, Roberts DJ, Rabi DM, Winston KY. Diagnostic accuracy of fine needle aspiration biopsy for detection of malignancy in pediatric thyroid nodules: Protocol for a systematic review and meta-analysis. Syst Rev. 2015; 4:120-.

6. Khattak RM, Khattak MNK, Ittermann T, Völzke H. Factors affecting sustainable iodine deficiency elimination in Pakistan: A global perspective. J Epidemiol. 2017; $27(6): 249-57$.

7. Omar MS, El-Sayed Desouky D. Environmental, urinary iodine status and prevalence of goitre among schoolchildren in a high altitude area of Saudi Arabia. Pak J Med Sci. 2015; 31(2):414-9.

8. Kutluturk F, Yildirim B, Ozturk B, Ozyurt H, Bekar U, Sahin S, et al. Thyroid dysfunctions and sonographic characteristics in northern Turkey: A populationbased study. Ann Saudi Med. 2013; 33(3):253-9.

9. Adam MA, Thomas S, Youngwirth L, Hyslop T, Reed $\mathrm{SD}$, Scheri RP, et al. Is there a minimum number of thyroidectomies a surgeon should perform to optimize patient outcomes? Annals of surgery. 2017; 265(2):402-7.

10. Yan HX, Pang P, Wang FL, Tian W, Luo YK, Huang W, et al. Dynamic profile of differentiated thyroid cancer in male and female patients with thyroidectomy during 2000-2013 in China: A retrospective study. Scientific reports. $2017 ; 7(1): 15832$.

11. Huang C-F, Jeng Y, Chen K-D, Yu J-K, Shih C-M, Huang $S-M$, et al. The preoperative evaluation prevent the postoperative complications of thyroidectomy. Ann Med Surg (Lond). 2014; 4(1):5-10. 
12. Vanderpump MP. The epidemiology of thyroid disease. British medical bulletin. 2011;99:39-51.

13. Zakaria HM, Al Awad NA, Al Kreedes AS, Al-Mulhim AM, Al-Sharway MA, Hadi MA, et al. Recurrent laryngeal nerve injury in thyroid surgery. Oman medical journal. $2011 ; 26(1): 34-8$.

14. Mobayen M, Baghi I, Farzan R, Talebi A, Maleknia SA, Paknejad SA. Comparison of the results of total thyroidectomy and Dunhill operation in surgical treatment of multinodular goiter. Indian J Surg. 2015; 77(Suppl 3):1137-41.

15. Kandil E, Noureldine SI, Abbas A, Tufano RP. The impact of surgical volume on patient outcomes following thyroid surgery. Surgery. 2013;154(6):134652; discussion 52-3.

16. Hauch A, Al-Qurayshi Z, Randolph G, Kandil E. The importance of surgical volume on outcomes in thyroid surgery revisited: Old is in again. Annals of Surgical Oncology. 2014; 21(12):3721-2.

17. Lee YS, Nam KH, Chung WY, Chang HS, Park CS. Postoperative complications of thyroid cancer in a single center experience. Journal of Korean medical science. 2010; 25(4):541-5.

18. Yadav SK, Mishra SK, Mishra A, Mayilvagnan S, Chand G, Agarwal G, et al. Surgical management of primary hyperparathyroidism in the era of focused parathyroidectomy: A study in tertiary referral centre of North India. Indian journal of endocrinology and metabolism. 2019; 23(4):468-72.

19. Ahmad Z, Kutaiman D, Khan A. Complication rates of thyroidectomy by an experienced, high-volume thyroid surgeon in a private hospital in Abu Dhabi, United Arab Emirates. Hamdan Medical Journal. $2017 ; 11$.

20. Baldassarre RL, Chang DC, Brumund KT, Bouvet M. Predictors of hypocalcemia after thyroidectomy: Results from the nationwide inpatient sample. ISRN surgery. 2012; 2012:838614.

21. Suwannasarn M, Jongjaroenprasert $W$, Chayangsu P, Suvikapakornkul R, Sriphrapradang C. Single measurement of intact parathyroid hormone after thyroidectomy can predict transient and permanent hypoparathyroidism: a prospective study. Asian journal of surgery. 2017; 40(5):350-6.
22. Seo ST, Chang JW, Jin J, Lim YC, Rha KS, Koo BS. Transient and permanent hypocalcemia after total thyroidectomy: Early predictive factors and longterm follow-up results. Surgery. 2015; 158(6):1492-9.

23. Papaleontiou M, Hughes DT, Guo C, Banerjee M, Haymart MR. Population-based assessment of complications following surgery for thyroid cancer. J Clin Endocrinol Metab. 2017; 102(7):2543-51.

24. Baloch N, Taj S, Anwer M, Naseem M. Frequency of Hypocalcaemia following Total Thyroidectomy. Pak J Med Sci. 2019; 35(1):262-5.

25. Joliat G-R, Guarnero V, Demartines N, Schweizer V, Matter M. Recurrent laryngeal nerve injury after thyroid and parathyroid surgery: Incidence and postoperative evolution assessment. Medicine (Baltimore). 2017; 96(17):e6674-e.

26. Barczynski M, Konturek A, Cichon S. Randomized clinical trial of visualization versus neuromonitoring of recurrent laryngeal nerves during thyroidectomy. The British journal of surgery. 2009; 96(3):240-6.

27. Shindo M, Chheda NN. Incidence of vocal cord paralysis with and without recurrent laryngeal nerve monitoring during thyroidectomy. Archives of otolaryngology--head \& neck surgery. 2007; 133(5):4815.

28. Khanzada TW, Samad A, Memon W, Kumar B. Post thyroidectomy complications: The Hyderabad experience. J Ayub Med Coll Abbottabad. 2010; 22(1):65-8.

29. Fan C, Zhou X, Su G, Zhou Y, Su J, Luo M, et al. Risk factors for neck hematoma requiring surgical reintervention after thyroidectomy: A systematic review and meta-analysis. BMC surgery. 2019; 19(1):98-.

30. Tartaglia F, Giuliani A, Sorrenti S, Tromba L, Carbotta $S$, Maturo A, et al. Early discharge after total thyroidectomy: A retrospective feasibility study. G Chir. 2016; 37(6):250-6.

31. Vrabec S, Oltmann SC, Clark N, Chen H, Sippel RS. A short-stay unit for thyroidectomy patients increases discharge efficiency. J Surg Res. 2013; 184(1):204-8. 


\begin{tabular}{|c|l|l|l|}
\hline \multicolumn{3}{|c|}{ AUTHORSHIP AND CONTRIBUTION DECLARATION } \\
\hline Sr. \# & \multicolumn{1}{|c|}{ Author(s) Full Name } & \multicolumn{1}{|c|}{ Contribution to the paper } & Author(s) Signature \\
\hline 1 & Mohammad Sohail Asghar & $\begin{array}{l}\text { Literature search, } \\
\text { Interpretation of data. } \\
\text { Literature search and review. }\end{array}$ \\
\hline 2 & Ahmad Kaleem & $\begin{array}{l}\text { Final proof reading of the } \\
\text { article and composing. } \\
\text { Literature search, } \\
\text { interpretation of data. } \\
\text { Literature search, } \\
\text { interpretation of data. }\end{array}$ \\
\hline 5 & Ameer Afzal & Usama Shabbir & $\begin{array}{l}\text { Reference writing and } \\
\text { formatting. }\end{array}$ \\
\hline 6 & Mohamal Anwar & \\
\hline
\end{tabular}

